\title{
THE PSYCHIATRIST VIEWS CHILDREN OF DIVORCED PARENTS
}

\author{
Janes S. Plant*
}

The Essex County Juvenile Clinic serves children who are "problems"-thumbsuckers, bedwetters, the shy, truants, runaways, etc. These are referred to the Clinic by courts, schools, social agencies, and parents themselves. Of the last one hundred who came to us only forty-five were living with their own parents. At first sight it would appear that there must be some dreadfully important relationship between family breakdown and the appearance of conduct disorders in children.

\section{The Value of the Data}

But for a while this conclusion must remain on probation. All physicians see only failures. A divorce resulting in freedom and a ringing, clear challenge to each one involved would never come to his office. A doctor would say that all people who eat pickles get stomach-aches-because these are the only ones he sees. The present overweaning interest in the psychiatrist's views on various subjects often tends to forget this "negative" skew to all of his data.

There is a further stricture on our data. Children are delinquent only when they are brought to court. Divorce, similarly, occurs only when two people have decided to turn to an outside agency for help in solving their problems. Perhaps this whole symposium tends toward a discussion not only of family tension but also of the extent to which individuals turn to others for assistance. The two matters are not mutually exclusive-they overlap and intertwine-but we must not forget their separate emphases. Divorce and delinquency-even the matter of turning to the psychiatric clinic-are sociologically oriented phenomena. They have to do with psychological problems and tensions but they are not accurate measures of those tensions. As long as a phenomenon which has psychological origins is described in terms that are purely sociological, there can be no such thing as reliable data ("reliable" is used here in the scientific sense of "data from which predictions as to probability can be made"). From various other data that I have I am sure that divorce can be an easy step for a namby-pamby pair of easy-goers. I am sure

- A.B., 1912, Sc.D., 1938, Hamilton Coilege; A.M., 1913, M.D., 1918, University of Pennsylvania; Fellow of the American Medical Association; Fellow of the American Psychiatric Association; Fellow of the American Psychological Association; Assaciate Fellow of the American Academy of Pediatrics. Resident Physician, American Hospital, Neuilly s/Seine, France (1919-1920); Pathologist, McLcan Hospital, Waverly, Mass. (1920-1922); Assistant, Judge Baker Foundation, Boston, Mass. (1922-r923); Director, Essex County Juvenile Clinic, Newark, N. J. since 1923. Author of Personality and the Cultural PATtern (1937) and of various contributions to psychiatric, sociological, educational and pediatric publications. 
that at times, it is a brave, difficult decision on the part of two honest persons. Or at one time or another it may be anything between these two extremes. How utterly strange this must sound to the lawyer for whom divorce can mean but one thing -modified, it's true, by certain revisions of the statutes! Neither is right or wrong -the psychiatrist and the lawyer deal rather with two entirely different evaluations of the same thing. As though one described an automobile in terms of the manhours it cost, and another in terms of the freedom or bondage it repaid its owner.

But we can look at the matter differently. We can cease to consider the sick person as weak (asking what is wrong with him) and begin to look upon him as sensitive (asking what he is trying to tell us). The tuberculous tells us that all persons need good housing, fresh air, good food. The many who died of typhoid fever were the sensitive ones showing us that every one needs pure water and pure milk-once we stopped to ask them what they were trying to tell us. So these divorced parents and their children who come to us may well be the sensitive ones -telling us in their own way what are the stresses upon all children of divorced parents, and upon all of the marriages of our culture-if we but ask. The data of this article may well be of value for us so long as we do not ask what it proves but rather as to where it bids us turn our faces.

\section{The Data Upon Which the Article Is Based}

The remarks of this study are based on three bits of data. A more complete study of all of our material might force some changes-but, I guess, not too great.

First I took our last yoo cases. Of these, as I have said, only 45 were living with their parents. For 25, one of the parents had died and in most instances the child was living with the other, though a few of these were in foster homes. For 8 others one parent was dead but there was a stepparent (the home established through remarriage). In the case of 20 , there was separation of the parents but not divorce. In all of these the children were, in varying degrees, in touch with one or both parents. Some lived with the mother-occasionally seeing the father. Some were in foster homes-having occasional or frequent contacts with one or both parents. Only 2 of this group were children of divorced parents. There are many -very diverse-reasons for bringing children to us but we have some justification for assuming that in general the more disturbed individuals come our way. On this basis it is striking that we have ten times as many children from separated parents as from divorced parents. Is it not possible to assume at least provisionally that divorce is a "solution"-that it represents something done about a problem? One does not say that it is the best solution. Perhaps these parents are of stronger or more forthright sort (with children, then, of a little better heredity); perhaps the answer is that a chapter of turmoil for the whole family group has been closed -we don't know. From this sampling of data (and I have no reason to believe that any other group of our cases would differ) there is surprisingly less disturbance in the children of divorced parents than in those of separated parents. 
I couldn't feel that these two children would make a very fair basis for reportso went further back in our files to find our last five children who are of divorced parents. There are three girls and two boys-would their problems seem to the casual reader-to be any different from those of the two hundred or more from whom they were culled?

Daisy Dixon is a plodding, conscientious fifteen-year-old, quietly looking out on the world in a sort of perpetual amazement that it has so much to worry over. She has lived with her mother, plugged along in school, gotten average grades, had a few girl friends-equally colorless-and, so far as anyone can determine, has not missed her father who was divorced some three years ago though there was earlier considerable family squabbling and some years of working at reconciliation. She is of modest ability, one of those whom her peers would call a "dope." She was brought because the mother "wondered why she wasn't making a better go of things in school." It soon turned out that Daisy was doing quite as well in school as she had ever done-and that the mother was considering an early remarriage. What would this do to Daisy? We thought that she might have asked Daisy which, indeed, it turned out that she had. With our more subtle techniques and analyses we got precisely the same answer as the mother-that Daisy subscribed in full to a policy of live and let live-that as long as there is food and shelter without serious dislocation of the law she asks no questions.

So we gave our blessing to the marriage which is soon to occur. Often parents bring their children as a cloak for their own problems of guilt or reassurance.

Geoffrey Lincoln had much the same basic reason for coming-but was responding to it in a different way. He's I2-doing a good job in sixth grade and could be in the seventh as far as ability is concerned. His mother, too, considers remarriage but is much on the fence about it. Her first venture was a terrible affair and certainly she has never regained the morale lost as she saw woman after woman take her husband from her. She would love to marry again-but does she dare to put her skill and personality once more to this test? So you won't be surprised to learn that Geoffrey is a restless, "nervous," lad who sucks his thumb, can't concentrate on his lessons, wets the bed and twice a week or so has terrific nightmares. It's not too easy to know how these troubles are going. Are they really getting worse, or is it that the mother just can't accept at 12 what wasn't too bad or unusual at 8 , or-once more-is the sharpening of the problems of her own life a catalytic agent in having her suddenly feel the intolerable burden of Geoffrey's troubles?

There would be as many "explanations" of Geoffrey's difficulties as there are psychiatrists. Nor is this the place to parade those assumptions. It is at least possible that there is nothing specific about his trouble-that any so serious a disturbance in his family would have produced as many nightmares-and nails as completely bitten back. I find it hard to tie his behavior to the divorce-the mother's 
complete failure in holding that which she so much wanted, her panicky terror over the question of a new alliance, these are the matters which I; for myself, take as the important ones. For her-it is to be admitted-the divorce (even though she instigated it) was a final crushing defeat. We see that the defeat was there to begin with-probably long before even the marriage-but I am sure that she has always seen the final decree as the living, driving symbol of all her miserable failure.

It's on this basis that we are treating the situation. Geoffrey will, I suppose, continue to wet the bed until he leaves the mother or until she faces her perplexities with a firmer faith in her own judgment and abilities.

Stephen Brown has a brilliant mind most of which is occupied in the punishment of two parents each of whom is remarried after a divorce of some four years' standing. Neither parent had come to court with clean hands-a matter which the Chancellor easily solved by giving the child to the mother, demanding some allowance for him from the father, but granting the father rights of visitation together with the permission to keep the child for even extended periods if the mother agreed. This has caused much conflict for both parents-each would love to keep the child from the other as a matter of continuing the guerrilla warfare, each is equally anxious to visit Stephen on the other as a close approximation to the plague. He's a bright-eyed genius of ten who can destroy more neighborhood property more efficiently than any other of some 10,000 children whom I know. The particular objects of his deviltry are the two new stepparents, but he does a creditable job with his grandparents who by now as roundly curse the first Brown marriage, as does anyone. It was the breaking of thirty windows in the elegant apartment house where Stephen was living with his mother, that brought him to us. Already bitter and determined, will he ever rest until these two selfish adults who never wanted him anyway have been driven to their graves? Divorce had nothing to do with this problem. Well, that's not a fair statement-a different Chancellor would have placed this six-year-old away from either parent-until one or the other had proven that he (or she) wanted Stephen in his own right and not just to bedevil the other. That wouldn't have been a good solution but it would have been the least damaging way out of a terrible mess.

We haven't known Stephen very long. He's in a boarding school. The startling calm that followed his going away has already been too much for the parents who find themselves with no ammunition for their warfare. They've tried to get him home-and I guess they'll soon be succeeding. The labors of Cisiphus are as nothing compared with helping people when they really don't want your help.

Luckily the Brown parents will be driven by this lad to an early grave. Stephen will live a long, bitter, expensive revolt against all who mean parents or authority or control. Even in these tender years a somewhat cherubic face smiles with the satisfaction of a good day's work done. I've never had the courage nor the dishonesty to disagree with him. 
Isabelle Andrews is of the sort that makes you fight for reform. The whole business is so meticulously correct legally and so miserably wrong as people go. She's an average, attractive 14-year-old who goes to high school by day and for the rest of the time is tied up with as conscienceless and miserable a group of ne'er-dowells as I know. Her father has her stubborn self-will and was divorced by his nice, proper, hard-working wife because of a new alliance-soon consummated. That was seven years ago. There are few who have worked as has Mrs. Andrews to retain in some small measure the things which they had earlier had. She came to court with clean hands so of course she has the child. We came into the situation only recently but we have no reason to doubt the mother's story that with her long working hours and her irritable fatigue when she got home, it wasn't long before Isabelle began to drift. Physical maturity brought a hard, brazen, sophisticationand the war with its footloose men has played its part. You can't, whatever the reason, just leave a child to its own devices for all these years without cultivation and have any result but a weed.

Only small children like unclean hands-and I musn't advertise my immaturity. So the Chancellor was right-or was he? Couldn't anyone have seen what a wretched failure was bound to come? If the family had had less of material resources before the divorce, or if the mother had tried less heroically to give Isabelle something of what her earlier life had been, that might have helped. But it still seems that when the court so virtuously invited this woman to travel so hard and so long a road it doomed both her and the youngster. The mother will wonder her whole life whether virtue has any rewards; Isabelle already knows that it hasn't.

This is expensive business. Each plan, each scheme, each honest goal will make its mistakes-but can't the very shock and authority of the divorce proceedings be used to further some inquiry, to mark out some pattern (and to implement it a bit) towards the building of better lives? So far as I know it, Society majestically inquired who was the injured party-who had been wrong-and sent the bunch on to destruction.

It's not too different with Josephine Black-though she's not like Isabelle today. Like Stephen, Josephine flashes by one's view-a striking, attractive vivacious girl of 16 whose many able talents are stuck as so many barbs in the various tender parts of her amazed and completely baffled stepfather. An otherwise most acceptable and promising marriage was rapidly on its way to the rocks when we first (not too long ago) knew Josephine. Even now from the "safe" distance of a nice boarding school she is carrying on a long-range barrage with fairly accurate aim. Her father was like that-brilliant, impatient, stubbornly sure that his was the right way. (At least both Josephine and her mother tell us this.) I don't know why he left home -the mother tells of a man who couldn't bear the day by day demands of a house and family. Josephine tells of one driven away by the mother's nagging, that Josephine alone understood him. She alone will carry his part through these years; 
she alone will make the mother regret those earlier steps and will drive the stepfather to harried retreat. The girl is a miserable failure in school. Only the Devil himself could conjure the hundreds of ways in which she can mortify her nice mother and make the stepfather wonder how he could ever have stepped into this biting steel trap.

Here, once more, wasn't there some place along the road where the adults involved could have been helped to see what must happen during the trying years of separation and possible reconciliation? I don't think so; the sores are too fresh and sensitive. Divorce often comes as a kind of closing of a stormy book. Could the occasion of divorce not be a time for looking ahead as well as of assaying the past? Perhaps we can set our faces towards freedom to do what, rather than towards freedom from what.

Josephine will land on her feet. She won't be a happy adult-but at least she won't be socially expensive. Her husband will pay for many of her parents' mistakes, but you and I won't be too aware of it. Yet things could have been better.

You know all of these five children. They live up or down your street-they may even be your relatives. They are not children of divorced parents but rather children-ones whose parents happened to be divorced. There isn't one "symptom," any one pattern of behavior, that belongs to them.

I have gone further afield for the data. Through the years we have seen many children of divorced parents and out of this experience have crystallized certain notions, certain provisional hypotheses which are not too reliable in themselves but have certain value when tempered with the I03 cases mentioned above. It is tempting to cite cases from that experience but such accounts would tend to be too florid. The ones that come from that quaint custom of awarding the child to each of the parents for alternate periods would make lively writing but you wouldn't believe the stories. Apparently it remained to modern Solomons to be the ones to really cut a child in two. And those from situations where the court granted certain rights of visitation in disregard of every consideration other than that the parent made certain monetary contributions to the child's upbringing, almost match them.

\section{Divorce And Insecurity}

From these three sets of data or experience what can the psychiatrist say of divorce as it affects the children?

The family, in our culture, gives to the child what we will now call "security." Here the word is used in a sense different from the ordinary. It is meant to cover the fact that a child has there a place because of "who" he is. He may be lame, or dumb, or with this or that defect-he may be mean or a bully but he still has a place because of just being himself. Outside of the family he may or may not get "adequacy"-a term to cover strength or "looks" or possessions or intelligence. For the length of this particular article we, then, won't speak of "financial security," using rather the word "adequacy." Words don't matter so much as long as we see 
that the only thing you can't take away from the child is the fact that two people were his parents and that thus they provide a certain orientation which is unassailable and sure. Note that there is nothing "reasonable" about this-the queerest parents, the queerest children-but in any case they belong. Adequacy is a reasonable affair. I can carry it in my pocket, I can express it with words, I can lose itto get it again another day. Not so with security-it wouldn't help me to feel that next week my mother will love me.

In our culture security comes to the child from' his family and from his church. God cares for him because he is that person-regardless of clothing or power or appearance. (Note that in a totalitarian state this security is given by the Statewhich is perhaps the reason for the attacks upon the Family and the Church in all totalitarian cultures.) However, the Church does not touch all of our children and, even where it does, the child is fairly well grown before he feels this side of its contribution. So, to all intents and purposes, it is his family, and that alone, that ministers to his security needs.

In many families this doesn't occur. You know such groups-where the child's intrusion was resented by one or both parents, where he is cared for only if he is handsome or intelligent, where he is suffered for some debt the family must pay its ancestors or cousins (to bring high honors from this or that school), where his care or expense lays only another heavy burden upon a marital relationship already dangerously sagging. The psychiatrist cannot over-stress the importance of this security or its lack; neither can the lawyer who recalls at the moment ten families of poverty, struggle and stark threat where this unreasonable tie of love or security has held the group together and been the firm foundation of future growth.

Perhaps an example in comparison will help. Two children-each has lost his father, one by death, the other by desertion. From the point of view of adequacy the second might be much "better off" than the former. The deserting father may be sending money, etc. But if you talk to these two children you find the one able with brave face and clear eye to tell you that his father died; the other hangs his head or concocts the most outrageous lie-anything to cover the fact that the father doesn't love him.

Adults need security too. In husband or wife or child they also seek these ties which all the buffets of the world's trials can't shake. Note that when adequacy has its darkest days, there is even every tendency for security to seem to grow and strengthen. And it is the obverse of this last phenomenon that makes security seem less important to adults than to children: We who are grown up tend to rest our status on adequacy; we know many nice families where there is so much of adequacy (beauty, charm, money, power) that the grown-ups have forgotten all about the security needs of people.

This has been a long introduction to the point that for the psychiatrist divorce is a mere incident in a rejection (insecurity) situation that has long since done its 
damage. Indeed, frequently the divorce represents a tremendous relief for the child. This is by no means always true-but it is true that at the Clinic we see many more children of separated parents than of divorced ones. In both instances the insecurity arising from the fact that the paramount interests of the parents are elsewhere is present, but the certainty and the finality of the divorce at least stops the daily quarrels, the daily scanning of the omens for the future, the daily rubbing of salt in the wounds.

I've had to guess the figure but it is somewhere around one in fifteen or twenty (of our own cases) where all of the real damage has not been done to the child long before the divorce. And isn't this something of what the situation is for the adults? Admittedly for one in each twenty or less the divorce proceedings and decree are a single terrific compelling blow. They are proof of something one "just couldn't believe was happening." 'That occurs with children but it is the exception, not the rule.

So the children of divorced parents are insecure; whatever their appearance, you will find somewhere a panicky loss of morale, a figurative hanging of the head. As they grow older they may cover this with bitter driving punishment of others, or they may guard and possess wife and children with an ever-hungry zeal. Or they may encapsulate all this part of life, defending it with a thick shell that defies memory or your intrusion. But it isn't the divorce that is important-well, perhaps this isn't a fair statement on the basis of our material; perhaps we had better say that for most it isn't, for a few it is and for more than a few it's something between those two extremes.

\section{Some Psychiatruc Complications in Family Breax-Up}

To understand the problem and the court's part in it, then, we are driven back to those conditions which surrounded its development. This would involve a dissertation on marriage which I am not going to attempt. As the family breaks, however, there are four complications which are seen often enough to require some statement before one attacks the therapeutic or remedial matters.

In quite a number of families the press of adult problems means that the child or children have been completely forgotten. I think of a family of five grand youngsters-from 18 to 6 . A woman who for years had been the mother's dearest friend suddenly loomed as a new interest for the father. The fiery flame of struggle for those three adults has burned for five years and not a thought has gone to the children. Oh, they've been fed and clothed. Their ears are clean and the hair brushed. They've even had trips to the zoo-but they are really as neglected as though their parents had walked away. For the troubled years, and finally the divorce, there never seems to have been any realization that the children were also parties to the transaction. This complete adult absorption in their own affairs is a fairly frequent complication. Some lawyers whom I know do a beautiful job in this area though mostly it's our experience that the lawyer is chiefly occupied in 
seeing to it that his client gets what he or she wishes in court. Perhaps here one opens the door for the judge of some future time.

There is another complication-somewhat more frequently seen-in that one or another child is rejected as being identified with the rejected partner. Josephine Brown feels that she "belongs" to the father-the mother feels the same and keeps her because here, at least, is one person of the father's sort whom she can control and master. So because the mother must work out her frustration and because the father comes to court with unclean hands, Josephine goes with the mother. Often it works out in this way. At other times the mother rejects a boy or the father a girl - or there is rejection of certain ones due to traits rather than sex-amounting to a pretty complete wrecking of the child's life because of identification with all that is feared and hated in the partner.

Somewhat less often one gets much the same result from a quite different source. We first knew John Joyce at six-coming to us with a catalog of complaints that pretty well covered each of the day's twenty-four hours. One searched in vain for a single word of praise. Admittedly he was an unprepossessing little nubbin who in whining ways was doing his level best to show the world his distaste of all it offered. The marriage was a mess, ending finally in a divorce. It was a mess from the start. It was based purely on the love of conquest and both parties soon realized this, though possibly they didn't put it into words. John was a last desperate effort at holding the union together and within a month had become the living present symbol of its folly. In marriages of this sort the child has no champion. He is the scape-goat and the sooner he is out of the presence of either parent, the better off he is.

There is, finally, a group of three situations which-as one or the other-we see with considerable frequency. In each of these the child is used by one or both parents as sort of a pawn in the game.

Frequently (Stephen Brown is reported above) the child is used to punish the partner. The boy's demands for toys, clothes and advancement are anxiously urged upon the burdened father; the girl's ability at housework is pushed and praised to break the spirit of an harassed mother. It isn't above the nicest parents to point a flaw, with no disappointment were the child to magnify it; and where there are these bitter adult struggles that particular form of attack grows apace. Children are cóached in the absence of the other parent. Usually this is a one-sided game, the child supporting only one of the parents. Sometimes, if the child is quite bright, it will sell out to the highest bidder at any given time.

Much less frequently the youngster is used to hold the other parent. I usually see this in the form of the mother trying to hold the father, but the opposite also occurs. Here the child may be even quite disliked by the mother who gives it every solicitous care and assures the father that it needs them both. The bright child soon realizes the situation and forces the mother to buy cooperation at a high price. This spoiled, whining object by now has her at her wit's end-hating 
him because of his behavior, forced to play the loving parent because in this way alone does she think that she can hold the father.

Finally, we occasionally see a parent currying the favor of one or another child as a means of bolstering a faltering ego. For either the father or mother the period preceding divorce is often filled with self-condemnation; one doesn't relish the crumbling of a great undertaking. So the dependence or loyalty of this or that child is of tremendous help and is often nurtured along in proportion as the adult rift widens.

In these three situations the position of the child soon turns out to be about the same. In all he is being used for a purpose, security or love become secondary. He may resent this playing on his deepest needs, he may coldly hold out for a good price, he may be simply dazed and confused over the conflicting tensions pressing on his life. I suspect that the law can never take cognizance of these matters further than giving the judge a wide latitude of discretion. Can the solemnity of the divorce, and the time it takes to get it, be used by him to assay these parts of the whole matter? The psychiatrist assumes that, in most instances, the fact of seeking a divorce would mean that it should be granted. When individuals have gone that far in their planning those fragile subtle needs of a real family are gonenor are they of the stuff that is built by fiat.

\section{What to Do}

The question to which we must turn is that of what sort of a decree rather than whether or not there should be one. And in answering that question there seem to be at least the following preliminary considerations.

The fact of divorce and what it symbolizes is always damaging to the child Some pretty distressing things have happened to him-matters that will tinge his whole life. Therefore all decisions are to be in terms of what is least damaging rather than of what is best for the child.

I can't imagine a situation in which it is fair to the child to divide him. Whichever parent he goes with must thoroughly understand his basic need to feel that both parents did the best that they could under the circumstances. My need to feel that my father is a good man and my mother a good woman-and that they loved me-this is the cornerstone of any happiness in life. A very few parents can share the child without trying to divide his loyalties-but the court will do well to make its basic rule that one or the other have custody and control.

Life does not easily lend itself to even-handed justice. Nor are children too interested in clean hands. Could a time come when disposition of the children will be made on the basis of where they have their best chance for security, as the term is used in this article? This would mean a decree planned for the future instead of only trying to close the past. In such decisions the court would make some bad mistakes; in dealing with human health and happiness one accepts this as an expected error in any venture that plans much good. 
Where the child has been a pawn in the game it seems much kinder and more constructive that he be away from both parents, on probation. As long as parents use a child instead of caring for him because of who he is, it is damaging for him to live with either or both. This need not do away with support; it is saying to the parents that the court is not allowing visitation, and then custody, until these can be on the basis of what is good for the child.

Our experience has been that undue importance has been given to the factor of support and the rights it entails. This may be excellent law and an outsider dare not ask too lightly for change in matters that have centuries of experience back of them; but it's often hard on the children. Could we turn our faces towards decisions that boldly consider the rights of the children and that as boldly sought the money to carry these through?

Finally, the court must consider the rights of the adults involved. This article deals with the children and has proceeded on the basis of their needs. Parents are people, too. They are only a little less children than are the youngsters involved. If what has been written here has disregarded that-it is due to the title.

It would seem to the psychiatrist that these considerations place two problems before the court. Each of these interweaves with the other-one cannot tear them apart too easily.

Even if the final decree is but the acknowledgment of the existence and drive of a long series of events, it is, for many persons, a procedure of considerable solemnity. Moreover, after an endless procession of relatives, friends, neighbors and lawyers who have been marshalled on the one side or the other, the judge represents the first impartial person in the whole affair. For this reason the psychiatrist hopes that there will come a time when judges will take into consideration the kind of thing that this article has been expressing. If the answer is that they are not prepared in this field and cannot employ expert help, the counter-answer is that there is nothing written here which is beyond each day's common sense recognition of the ordinary needs of ordinary people. Perhaps the trained expert has here or there some trimming or addition of value, but for the most part the judge who is humbly courteous and has not any of his own axes to grind as to how people should live knows full well the hungers of persons.

But there is another task to which I would like to see the court address itself. This is that of using divorce as a means of bringing about a better world for all people. Every court knows the terrific price that America pays for its interest in material gain. Who other than the judge can point out-with data-the unhappiness that comes to those who do not basically seek to live in full and cooperating fashion with their fellows? We advertise higher education, refrigerators, cars, the American "standard of living"-all of those things which cost money. Well enough, those are fine. But haven't the young people the right to know that these are but the garments of life-and when will we dare tell our citizens that clothes don't make the man? I have known a good many young married people; they 
always start out with the notion that marriage will be successful. So divorce always means in some way or other a failure. But those failures could help so many others if they were used as teaching material.

Another great source of separation and divorce is intolerance. We want people to be what we think, or hope, they are. It is so seldom that husband and wife or child is allowed to be himself or herself. How busy each one is making everyone else over! Particularly during these war years are we free to make of husband or wife (thousands of miles away) what we want them to be. So there will be a great increase in broken families following the war. A husband can be so handsomely tender, a wife so beautifully efficient-so long as they don't have to live together! Once more it seems to me that the court has much to tell by way of help to all people; once more the court can make the divorce live and grow to make all marriages more understanding, more tolerant.

Earlier I pointed out that a democratic form of governance does not per se give security, in the sense that the word is used here. Thus if we are to preserve our democracy it can only be as we preserve and strengthen family life. American citizens have a way of doing those things they think are important. Would it be possible to show our people that the future of our form of government rests considerably more on the integrity of our family life than upon the amount of consumer goods we can manage to turn out next year?

But no one can battle with the problem of growth and adjustment that is involved in every home that's worth its salt without the faith of others, and this faith we haven't given to the adults of our families. For four generations various agencies (public and private) have been eating into the family's job; for two generations every conceivable sort of "expert" has been announcing that he or she knew how to do the job better. Johnny would be quite a nice lad were it not for his parents! Little wonder that now in war time they heed our word and go out to make money rather than continue to be "problem parents" in the home. Some of separation and divorce, much of delinquency, much of the present-day crumbling of family life is due precisely to this. Once more, could the court out of its experience challenge America to have faith in its parents? They would still stumble, but not so much as now.

So, perhaps one day, if it please the court to see it, divorce will have done more than anything else to strengthen family life in America. 